\title{
Article \\ A Methodology for Planning and Prioritisation of Rural Roads in Bangladesh
}

\author{
Md. Musleh Uddin Hasan ${ }^{1, *}$, A S M Abdul Quium ${ }^{2}{ }^{\circledR}$, Mashrur Rahman ${ }^{1}{ }^{\circledR}$, Farzana Khatun ${ }^{1}$, \\ Mohammad Shakil Akther ${ }^{1}$, Afsana Haque ${ }^{1}$, Sarwar Jahan ${ }^{1}$, Ishrat Islam ${ }^{1}$, Tanjeeb Ahmed ${ }^{1}$ (D) \\ and Tanvir Hossain Shubho ${ }^{1}$
}

check for

updates

Citation: Hasan, M.M.U.; Quium, A.S.M.A.; Rahman, M.; Khatun, F.; Akther, M.S.; Haque, A.; Jahan, S.; Islam, I.; Ahmed, T.; Shubho, T.H. A Methodology for Planning and Prioritisation of Rural Roads in Bangladesh. Sustainability 2022, 14, 2337. https://doi.org/10.3390/ su14042337

Academic Editor: Aoife Ahern

Received: 26 November 2021

Accepted: 28 January 2022

Published: 18 February 2022

Publisher's Note: MDPI stays neutral with regard to jurisdictional claims in published maps and institutional affiliations.

Copyright: (c) 2022 by the authors. Licensee MDPI, Basel, Switzerland. This article is an open access article distributed under the terms and conditions of the Creative Commons Attribution (CC BY) license (https:// creativecommons.org/licenses/by/ $4.0 /)$.
1 Department of Urban and Regional Planning, Bangladesh University of Engineering and Technology (BUET), Dhaka 1000, Bangladesh; mashrurmishu@yahoo.com (M.R.); tania.0415014@gmail.com (F.K.); shakil@urp.buet.ac.bd (M.S.A.); afsanahaque@urp.buet.ac.bd (A.H.); sjahan50@gmail.com (S.J.); ishratislam@urp.buet.ac.bd (I.I.); tanjeeb389@gmail.com (T.A.); shm.tanvir@gmail.com (T.H.S.)

2 Former Expert, UNESCAP, Bangkok 10200, Thailand; abdul.quium@gmail.com

* Correspondence: musleh_uddin@urp.buet.ac.bd

\begin{abstract}
Local government bodies and other concerned agencies in developing countries spend a considerable amount of money on rural road development. However, in the absence of any robust and systematic methodology, road development largely relies on ad-hoc decisions and subjective judgement of public officials. Such a decision-making process often leads to inefficient resource allocation bypassing equity and long-term societal benefits. Although there are some established methodologies for road network planning, complexities exist in applying those methods. First, most of the established methods are not suitable for rural road development, particularly regarding the volume and nature of traffic on them. Second, some methods are highly complex and lack practical applicability. Third, road development planning should not be top-down alone but ensure the participation of local stakeholders. Given these limitations, this study proposes a methodologyRural Road Planning and Prioritisation Model (RPPM). It consists of two major components (i) developing a core network in participation with local stakeholders and (ii) prioritisation of roads based on Cost-Benefit Analysis (CBA) and Multi-Criteria Analysis (MCA). The proposed method is piloted in one district, and a web-based software is also developed for practical implementation by the Local Government Engineering Department (LGED), Bangladesh. The paper also discusses the results of the pilot study.
\end{abstract}

Keywords: Bangladesh; CBA; MCA; Rural Road Planning and Prioritisation Model (RPPM)

\section{Introduction}

Rural road networks play a vital role in the economic development of a nation. In the context of developing countries, rural roads are essential for the transportation of agricultural products, poverty alleviation and accessibility improvement to basic facilities such as markets, schools and health care services [1-4]. However, inadequate rural road infrastructure-poor road condition, lack of accessibility and connectivity-can thwart the socio-economic development process of rural communities. The development of rural road networks, therefore, has become an all-important policy agenda for the developing world [2,4,5]. Many countries have implemented impressive rural road development programmes. In India, as part of the PMGSY scheme, 88 percent of all villages, (i) having a population 500 and above in plain land, and (ii) having population 250 and above in hilly/desert/tribal areas, had been connected by rural roads in between 2002 to 2007 to provide all-weather roads for [6,7]. In Sri Lanka, under the Gama Neguma programme, $3354 \mathrm{~km}$ of roads and bridges were built between 2006 to 2008 in 119 Grama Niladhari divisions, out of 14,034 divisions [8]. The Philippines is implementing an Intensified Building-Up of Infrastructure and Logistics for Development (I- BUILD) programme, 
funded by the World Bank, to develop a network of climate-resilient rural roads and other infrastructure and facilities [9]. As part of the target to provide transport infrastructure and bus service to all villages in the country by 2020, China constructed about two million $\mathrm{km}$ of rural roads during the period 1996-2004 [10].

There are multiple challenges in rural road development, which are well documented in previous studies. These include but are not limited to scarcity of funds, lack of technical expertise at local government bodies, geographic condition, weak governance and lack of transparency $[1,5,11]$. Road investments are largely made based on ad-hoc decisions and subjective judgement of local government officials $[5,11]$. This often leads to inefficient and inequitable distribution of limited resources, and omission of local views and interests. Therefore, a systemic methodology is required, which can be practically applied by professionals and government officials for the planning and prioritisation of rural roads.

There are several approaches available for prioritising road development; the most common types are network-based models, multi-criteria analysis (MCA) and economic analysis (e.g., cost-benefit analysis) [9,12-16]. However, complexities exist in applying these methods for rural road development, especially in the context of developing countries. First, most of these methods are developed considering urban roads with high traffic volume, and the main objective is to reduce traffic congestion and maximise travel time saving. These methods are not suitable for rural roads, having different volumes and nature of traffic compared to urban roads. Second, some methods are highly complex, which are difficult to replicate in other places and lack practical applicability. Third, road and connectivity development should not follow a top-down approach alone. Local stakeholders can provide critical inputs in such decisions.

Considering these limitations, in this study, we have developed a robust, participatory and practical methodology - Rural Road Planning and Prioritisation Model (RPPM). The RPPM has two major components- (i) planning core network and (ii) prioritisation of road development based on a set of physical, economic and social criteria. The proposed methodology is applied in the context of Bangladesh and a web-based software is developed for the field application. The RPPM has been successfully tested for one district by the Local Government Engineering Department (LGED), Bangladesh.

The paper is organised as follows. The context of rural road prioritisation in Bangladesh is presented next. This is followed by a review of existing methodologies and tools for rural road planning development appraisal. The next sections discuss the road development practices by LGED and other developing countries. Then the paper presents and discusses our proposed methodology. The paper ends with the results of the field application and conclusion.

\section{Rural Road Development in Bangladesh: Problems and Challenges}

In Bangladesh, there is about $353,353 \mathrm{~km}$ of rural roads connecting some 87,000 villages with other settlements and activity centres and roads of the same and higher orders [17]. Type and condition of rural roads; volume and nature of traffic on them and their beneficiaries and users greatly differ. Local Government Engineering Department (LGED), under the Ministry of Local Government, Rural Development and Cooperatives (MoLGRDC), Government of Bangladesh, is the primary manager of all rural roads in Bangladesh. LGED's spending for maintenance and upgrading these roads is enormous and gradually increasing. Hence (optimum network) planning and prioritisation (for development) of these rural roads are essential.

There are three types of rural roads: Upazila, Union and Village roads. Of them, $74,000 \mathrm{~km}$ are paved, about 20,000 $\mathrm{km}$ are brick paved, which may be paved in the near future and the remaining length of rural roads, including 24,000 km Upazila and Union roads, are earthen and unpaved.

Many of these roads are vital to ensure rural accessibility and connectivity with the national and regional highways, and higher order national centres. The transport demand for passengers and goods has increased manifold over the years. Consequently, many rural 
roads, originally built for low volume light traffic, are found inadequate and substandard to cope with the growth of traffic; these roads need upgrading.

Planning and prioritisation of rural roads for development works should be selected based on a certain methodology so that the road network can be properly maintained over a longer term. Such a methodology also can enhance the planning and decision-making capacity and efficient resource allocation in LGED. There are also policy requirements too. The development of a simplified CBA methodology based on limited and available data for the appraisal of rural roads is a strategy stated in the Seventh Five Year Plan of Bangladesh [18]. As many villages in Bangladesh are not connected by all-weather roads, some broad criteria, similar to national programmes in other countries and target 9.1 of Sustainable Development Goal (SDG) target can be considered to develop rural road networks with a focus on affordable and equitable access for all.

In the past, simple appraisal methodologies were used to estimate the benefits of road improvement. But these methodologies were project specific. Currently, LGED uses a priority ranking model only for the prioritisation of road maintenance work. There are national level guidelines for rural infrastructure development, for example, Guidelines for Rural Roads and Culverts Maintenance (GRRCM) [19] and Rural Road Design Standards [20]. The GRRCM provides LGED with useful guidelines in maintaining its infrastructures and assets. Higher priority is given for periodic maintenance, higher order roads, donor funded roads, roads having higher traffic volume and bus routes, continuous and uninterrupted link providing roads, roads providing access to more growth centers, Villages, service/activity centers. Currently, an arbitrary appraisal for maintenance of the road is done in a two-step process. Table 1 shows some of the several indicators, their classification and assigned rating. In the first step number of all the indicators along the roads are identified and each indicator/group of indicators is then multiplied by their respective rating. In the next step, the summation of all the scores provides the total score of the road. Roads with a higher score are given higher priority.

Table 1. Criteria and their weights used by the road maintenance priority model.

\begin{tabular}{ccc}
\hline Criteria & Description & Weight/Rating \\
\hline Road type & Upazila road & 12 \\
\hline Surface type & Fully BC & 12 \\
\hline Gaps & Major gaps & 3 \\
\hline Traffic volume & Commercial Vehicle per Day (CVD) 300+ & 100 \\
\hline Market & Growth Centre & 12 \\
\cline { 2 - 3 } & Rural market & 6 \\
\hline Hospitals & Upazila/union health complex & 6 \\
\hline \multirow{2}{*}{ Social centres } & Union Parishad office & 9 \\
\cline { 2 - 3 } & Other public centre & 3 \\
\hline \multirow{2}{*}{ Educational institutions } & College & 6 \\
\cline { 2 - 3 } & Secondary school & 3 \\
\cline { 2 - 3 } & Primary school/madrasa * \\
\hline Madrasa: An educational institution with a primary focus on the study of Islamic Theology and
\end{tabular}

However, the criteria and their scores, as in the current prioritisation method, are arbitrarily set by LGED officials. In recent years LGED has developed a road database that maintains information on road characteristics, traffic counts by mode on the market and non-market days, etc.; socio-economic facilities along a road, etc. LGED has also developed a GIS database of roads and other infrastructures. There is potential, although 
limited, to utilise and integrate these two database to develop an automated planning and prioritisation tool.

Overall, the challenges of developing a methodology for LGED can be summarised as follows: (i) the methodology must be able to appraise all types of roads (low-high volume, paved-unpaved, etc.) for all possible types of development intervention made by LGED; typical CBA analysis cannot address all such roads and all types of development interventions; (ii) other than being entirely objective and top-down, the methodology should keep the scope to involve the local leaders and stakeholders in the planning process so that their suggestions and aspirations are reflected in the output; (iii) finally, yet the methodology should be simple so that the software developed based on this is easy to use, makes the best use of the available data from the existing databases and can enhance decision making in LGED.

\section{Study Approach}

Having reviewed current appraisal practices and government policies and strategies on rural road development in Bangladesh and other countries, several consultation meetings were arranged in the period 2016-2018 to receive feedback from LGED officials at local (Tangail district) and national levels to understand their current practices; availability of Road and GIS databases; and constraints in using these databases and continuing the practice. Several local and one national workshops were also organised, in the same period, with stakeholders including male and female elected representatives (local government and Parliament), local and national civil society representatives, government and nongovernment officials, subject experts, academics, and others. Analytical Hierarchy Process (AHP) was used for identifying and calculating relative weights of criteria used in the methodology. Reed-Muench Median Threshold Population Method [22] was applied to determine their relative weights of different socio-economic facilities, a criterion used in the methodology. Then the draft methodology and algorithm were developed and subsequently trialled locally. Then final methodology and software, named Rural Road Planning and Prioritisation Model (RRPM), were developed and validated with LGED officials both at Tangail and headquarters. The final methodology and RRPM were presented in a national workshop at LGED headquarters and then finalised in 2018.

\section{Review of Methodologies and Tools for Rural Road Planning Development Appraisal}

This section presents a review of the methodologies of rural road planning and development. The existing methods can be broadly grouped under three major categories(i) economic analysis (Cost-Benefit Analysis), (ii) Multi-Criteria Analysis (MCA) and (iii) network optimisation models. The following sections provide a brief overview of these methods:

Economic analysis (Cost-Benefit Analysis): The Cost-Benefit Analysis (CBA) is one of the most widely applied methods for road development prioritisation across the world. The CBA methods have gained popularity among decision-makers because it provides an economic basis for road investment decisions. Several standard CBA models are available, which are widely used in many countries. For example, the Worlds Bank developed (i) the Highway Design and Maintenance Model (HDM), which can only be used for roads with 200 or more vehicles per day [23-25] and (ii) the Roads Economic Decision (RED) model, adapted for unpaved roads with traffic volumes between 50 to 300 vehicles per day $[16,26]$. These and other CBA models identify and estimate all costs and benefits of a project in monetary terms during its lifetime, discount them (generally the present year), and evaluates if overall benefits outweigh costs. The commonly applied assessment criteria for project selection include Benefit Cost Ratio (BCR), Net Present Value (NPV), Internal Rate of Return (IRR), Payback Period, etc. There are several approaches to estimate the benefits of road development. The User Cost Saving (UCS), Vehicle Operating Cost Saving 
(VOCS) and Travel Time Cost Saving (TTCS), and Agricultural Product Surplus Method (APS) are among such conventional approaches.

Multi-Criteria Analysis (MCA): Multi-Criteria Analysis (MCA) techniques are also used for rural road prioritisation, especially in the context of developing countries $[9,13,27-30]$. In general, the ranking of projects is based on a set of factors or criteria reflecting policy or social objectives. Such factors may or may not include cost variables but may include variables such as population served, improvement of access to markets and services, impacts on natural systems, traffic volume, social and economic welfare, etc. After the selection of factors, their relative weights are established. The use of Analytical Hierarchy Process (AHP) is common for the establishment of relative weights of the factors. Finally, the priority score or index value of each candidate road project is calculated by summing the product of the value of each factor (often the actual value is normalised) by its relative weight.

Network Optimization Models: Transportation network optimizations models are widely used for road prioritisation, mostly for urban roads. Farahani et al. (2013) provides a detailed review of such models [12]. Few works have utilised network-based models for rural road developments in the context of developing countries. For example, Oudheusden and Khan [31] in Bangladesh and Shrestha et al. [32] in Nepal have applied some network development models such as the Minimum Spanning Tree (MST) and other network development models. In short, an optimum network of roads is identified by applying the MST model, which minimises the total length of the road network in connecting all Villages with the nearest market/service center. More recent works have used Geographic Information System (GIS) based models incorporating accessibility planning. Singh [15] has developed a methodology for rural road network planning in India. An Accessibility Index (AI) is designed to evaluate the efficiency of various rural roads/links in accessing the missing functions or unconnected settlements. A GIS-based technique for the analysis of the alignment of new road link options is developed, which considers the topographic and land use characteristics of the area.

Merits and Demerits of Existing Methods: Each of these methods, as discussed above, has its own strengths and limitations. CBA gained popularity among decision makers as it provides an economic basis for road investment. One major challenge of CBA is that it is very difficult to capture all direct and indirect benefits in terms of monetary values (for example, accessibility benefits). Another major criticism is that CBA is essentially an economic efficiency criterion; it does not consider equity or reflect local needs. MCA can overcome these limitations to some extent by considering socio-economic benefits arising from road development. However, MCA also has its limitations. The selection of criteria and level of importance attached to those criteria are questionable. Most importantly, the main caveat is the inability to compare the benefits with respect to the costs. Network-based models follow optimisation techniques such as cost and travel time minimisation. Such models also consider connectivity and accessibility benefits like MCA. However, most of the network-based models are developed considering urban networks, and therefore, are not suitable for application for rural roads considering the volume and nature of traffic. In addition, the complexity of network-based models poses a major challenge for practical application in the context of road prioritisation decisions.

While these mainstream approaches have unique strengths and limitations, hybrid methods can offer a distinct advantage over conventional methods. For example, Gühnemann et al. [33] combined MCA and CBA to capture the best of both. In another example, Shrestha [34], in his methodology for district road network planning and prioritisation in Nepal has used a network planning model, CBA, and a prioritisation index based on four criteria (agricultural potential, interaction, accessibility and environmental impact).

Another important concern is the lack of transparency of road investment decisions. Traditional methods fail to capture local needs and unique geographic contexts. In such cases, participation of local stakeholders and elected representatives can provide useful information for road prioritisation decisions. At the same time, it can potentially address social equity issues and bring transparency to road investment decisions. For example, a 
well-known method is the Integrated Rural Accessibility Planning (IRAP) methodology developed by the International Labor Organization (ILO) [35]. IRAP is an area-based planning process to identify the actual access needs of the local communities. It defines and prioritises interventions to improve access by improving rural mobility infrastructures (such as roads, bridges and tracks) or by the distribution of facilities and services (such as water supplies, schools and health centers). The whole process is participatory and involves local communities and agencies. The IRAP methodology has been applied in the Philippines and many other countries for Village level accessibility planning. Sarkar and Dash [36] developed a modified version of IRAP and applied it in India. Yet, participatory approaches such as IRAP have limitations too. For example, the methodology is complex and relies on extensive data collection, which is time consuming and requires local training [5].

\section{The Planning and Prioritisation Methodology Developed}

In this study, we propose a robust, practical and participatory method for rural road planning and prioritisation. Depending on the types of road development, we consider three prioritisation schemes. These are: (i) Improvement-converting an existing earth road to a paved road by Bituminous Concrete (BC)/Reinforced Cement Concrete (RCC) or a partly paved road to a fully paved road or a Herringbone Bond (HBB) brick road to a fully paved road; (ii) Further Improvement/Upgradation-Further improvement of road geometric standards, raising of embankment and widening of pavement and/or road crest and raising of road embankments of an existing road and (iii) Maintenance of an already paved or partly paved road (BC, RCC or HBB). An important consideration of road development is the physical characteristics of a road (determined by surface type). Based on the surface types and development schemes, our method generates eight separate priority lists (Table 2). This priority list shows which types of roads are considered for which types of development.

Table 2. Priority list of roads prepared by proposed methodology.

\begin{tabular}{|c|c|c|c|c|}
\hline $\begin{array}{c}\text { Type of Road } \\
\text { Development Type }\end{array}$ & $\begin{array}{c}\text { Roads Considered (Based on } \\
\text { Surface Type) }\end{array}$ & $\begin{array}{l}\text { Priority List to } \\
\text { Be Developed }\end{array}$ & $\begin{array}{c}\text { Appraisal } \\
\text { Methodology Used }\end{array}$ & $\begin{array}{l}\text { Prioritisation List } \\
\text { Based on }\end{array}$ \\
\hline \multirow{4}{*}{ Improvement } & Low traffic volume * earth road & 1 & MCA, CBA & MCA, CBA ${ }^{* * *}$ \\
\hline & High traffic volume ** earth road & 2 & \multicolumn{2}{|c|}{$\mathrm{MCA}, \mathrm{CBA}$} \\
\hline & Partly paved road & 3 & \multicolumn{2}{|c|}{ MCA, CBA } \\
\hline & Fully HBB road & 4 & \multicolumn{2}{|c|}{ MCA, CBA } \\
\hline \multirow{3}{*}{ Maintenance } & Partly paved road & 5 & & \\
\hline & Fully HBB road & 6 & & \\
\hline & Fully paved road & 7 & & \\
\hline $\begin{array}{l}\text { Further Improvement/ } \\
\text { Upgradation }\end{array}$ & $\begin{array}{c}\text { Fully paved (Full BC/RCC, } \mathrm{HBB}+ \\
\text { BC/RCC) }\end{array}$ & 8 & $\mathrm{MC}$ & CBA \\
\hline
\end{tabular}

Two appraisal methods namely, cost-benefit analysis (CBA) and multi-criteria analysis (MCA) are used for the improvement and upgradation of roads. The priority ranking of roads is based on the outcome of CBA and MCA. For maintenance, only MCA is considered. This is because BCA reflects the economic and financial worth of a new road development project, whereas maintenance is a recurring task. Therefore, instead of economic analysis, maintenance priority is determined by a set of defined criteria through MCA.

The methodology has two major components. The first component follows a network approach to road planning; and the second component involves prioritisation of road 
development based on assessments using a set of physical, economic, social and other criteria. Both the components include the provision of local stakeholders' participation in the process. Figure 1 shows the overall approach followed in planning and prioritisation of rural road development.

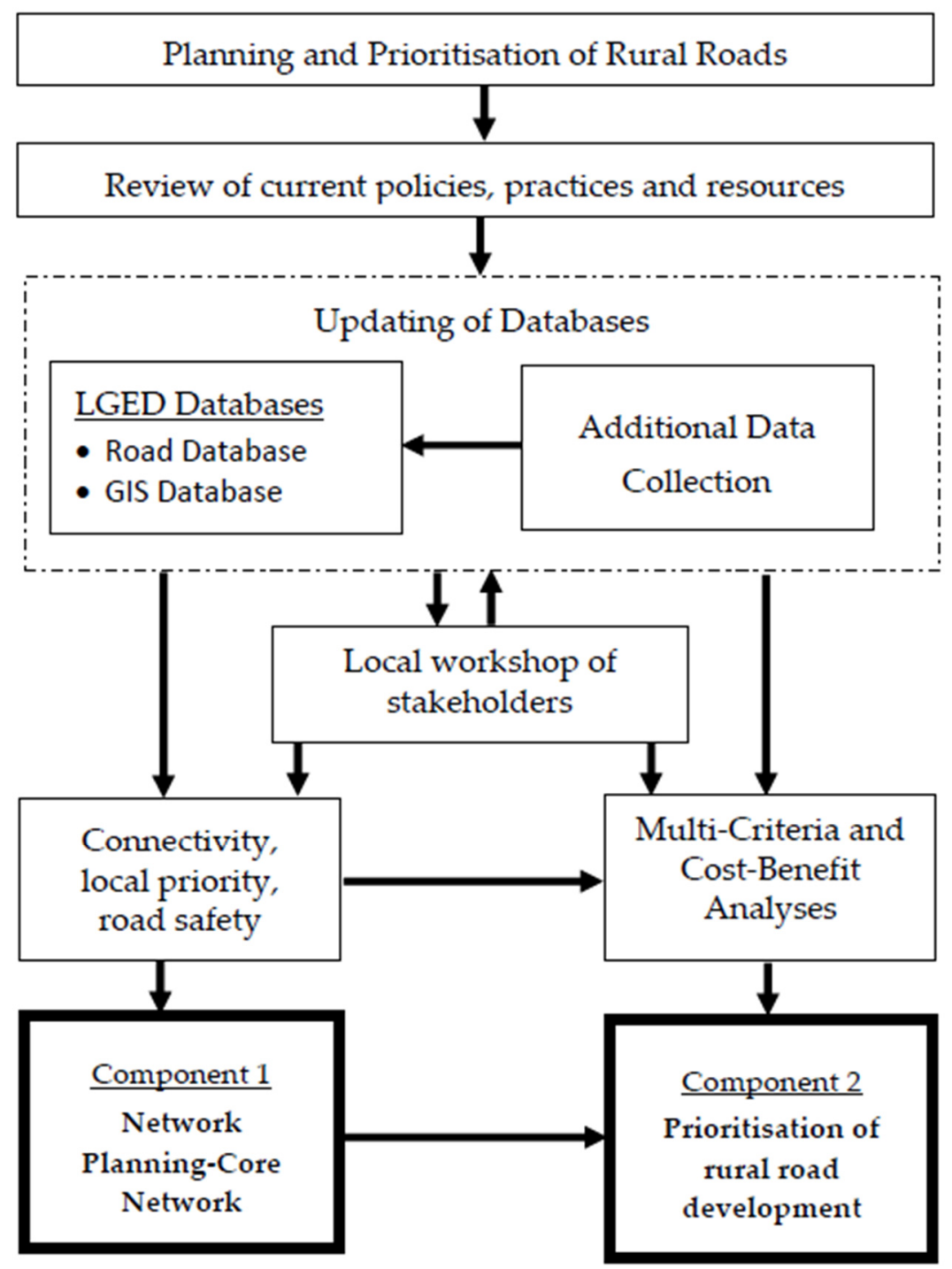

Figure 1. Schematic diagram showing overall approach of the RPPM.

All the designated Upazila and Union roads along with the national roads, if any, form the core network in an upazila. The core network also includes roads that cross the geographical boundary of an upazila to connect an activity centre or a national road in a neighbouring upazila. In the prioritisation scheme, all such roads have been given additional importance as together they form a network vital to maintaining inter- and intra-upazila transport connectivity. The activity centres form the nodes and Upazila and Union roads connecting them are the links of the core network.

The core road network has two components: upazila-level core network, and unionlevel core network. The upazila core road network serves upazila-wise access needs and ensures connectivity with the neighbouring greater region/rest of the country. The union core network serves union-wise and inter-village access needs and ensures connectivity with other areas of the same and neighbouring upazila(s).

The prioritisation component of the methodology considers criteria for the assessment of costs, benefits, and social and environmental considerations were selected. The selected 
criteria included road construction costs, direct benefits to road users, improved accessibility to markets and social infrastructure facilities, connectivity, if the road can be used in all seasons, and other local priority of special nature.

The organisation of local workshops is an important element of the methodology. Local stakeholders validate the core network generated according to the criteria discussed above. The stakeholders also define local priorities for the development and maintenance of roads, identify potential Upazila and Union roads that may need further development, and assess the connectivity status of the roads in the core networks.

A simplified CBA methodology has been developed which compares the benefits and cost of road development., Benefits are calculated in terms of savings in vehicle operating costs (VOC) and travel time costs (TTC), based on available database maintained by LGED and other secondary sources. For cost calculation, we rely on standard road development cost estimates provided by LGED. The cost estimation takes into account historical records of previous projects undertaken by LGED for various types of road development. The developed CBA model for the study estimates Economic Internal Rate of Return (EIRR) values for all roads that require improvement or further improvement, as defined earlier.

Prioritisation methodologies should not be based solely on the traditional economic appraisal of roads. Other important criteria such as, connectivity with higher order roads and benefits from enhanced access to socio-economic infrastructures should also be considered, which are difficult to operationalise in BCA. Further, rural roads provide access benefits to people living along the roads, many of whom may not be using any vehicular traffic. Therefore, in order to make a more complete assessment, the access benefits to people also need to be assessed by an MCA or some other methodology. For MCA, criteria such as traffic volume, number and type of socio-economic facilities, growth centre and rural market served by a road, connectivity and local priority have been considered. The applicable criteria for MCA were selected from among a list of potential criteria by conducting an Analytic Hierarchy Process (AHP) survey among the stakeholders including experts and LGED officials. After selection of the MCA criteria, their relative weights were also established using the AHP technique

As the actual values of the selected criteria are in different units of measurement and the range of their minimum and maximum values widely vary, the actual values were standardised on a common scale of 0 to 100 to allow for their summation. Finally, the priority score or index value of each road was calculated by summing the product of the standardised value of each criterion by its relative weight as follows:

$$
I=\sum\left(w_{i} \times x_{i}\right)
$$

where, $I=$ Combined score, $w_{i}=$ Relative weight of criteria $i, x_{i}=$ Standardised score of criteria $i$.

The priority order for the development of individual roads is determined on the basis of their combined scores.

Some socio-economic facilities are of the same type but do not have the same order of importance. For example, different types of educational institutions such as primary school, high school, college and madrasa. For these types of facilities, the Reed-Muench Median Threshold Population Method [22] was applied to determine their relative weights. Table 3 shows the selected criteria and their AHP weights for each type of road development.

Following the standard practice of the Analytical Hierarchy Process (AHP), initially, the pairwise comparison was done for the concerned criteria (Table 3 ) by the experts and LGED officials. Then a comparison matrix is developed using the relative importance of criterion $i$ comparing it with criterion $j$. Using this matrix, the weighting coefficients for each of the criteria are derived by calculating the principal eigenvector. The consistency check is performed for the comparison matrix in terms of consistency ratio (CR). The modification process is run couple of times in order to get the $C R<0.1$ for the consistent comparison matrix.

Figure A1 in Appendix A shows the decision tree for the selection of roads for development (intervention) types and priority ranking. 
Table 3. Selected criteria and their weights for each type of road development.

\begin{tabular}{ccccc}
\hline MCA Criteria & $\begin{array}{c}\text { Improvement of } \\
\text { Unpaved Roads }\end{array}$ & $\begin{array}{c}\text { Improvement of } \\
\text { Partly Paved } \\
\text { and HBB Roads }\end{array}$ & $\begin{array}{c}\text { Further } \\
\text { Improvement of } \\
\text { Roads }\end{array}$ & $\begin{array}{c}\text { Maintenance } \\
\text { of Roads }\end{array}$ \\
\hline Traffic Volume & 7.95 & 20.01 & 21.84 & 15.05 \\
\hline Facilities Served & 18.65 & 15.02 & 9.54 & 14.85 \\
\hline $\begin{array}{c}\text { Growth } \\
\begin{array}{c}\text { Centre/Market } \\
\text { Served }\end{array}\end{array}$ & 29.20 & 13.58 & 17.91 & 12.70 \\
\hline $\begin{array}{c}\text { Connectivity } \\
\text { Local Priority }\end{array}$ & 35.80 & 21.04 & 20.07 & 19.65 \\
\hline Surface Type & 8.40 & 5.97 & 14.93 & N/A \\
\hline Road Type & N/A * & 5.86 & N/A & 7.80 \\
\hline Road Safety & N/A & 11.83 & 7.86 & 14.15 \\
\hline Bus Route & N/A & N/A & 7.89 & N/A \\
\hline Last maintenance & N/A & N/A & N/A & 11.50 \\
\hline year & 100.00 & 100.00 & 100.00 & 4.30 \\
\hline Total & & & 100.00 \\
\hline
\end{tabular}

${ }^{*}$ N/A: Not Applicable.

\section{Local Stakeholder Participation in the RPPM}

Collecting and addressing feedback from local people and important stakeholders is a fundamental feature and strength of the RPPM. To apply the RPPM, at least one local workshop has to be organised at each upazila, i.e., sub-district. The workshop will have to be attended by the local leaders, officials and other stakeholders.

Considering its representativeness and suggestion of LGED officials, Tangail was selected as the pilot district to test the methodology and working of RPPM. The methodology was applied in 12 upazilas of the district. Hence, 12 local workshops were organised.

An upazila is consisted of several unions. Before the local workshop, based on the LGED database, two types of preliminary core networks were prepared by the study team: (i) one upazila core road network and (ii) several preliminary union core road networks. Then these preliminary networks were validated in the local workshop. Workshop participants ensured the inclusion of all important roads in the core network, even if those are not available in the LGED database. For example, during workshops, roads that connect an important activity centre (Growth Centre/important rural market/boat station/rail station or any other important economic/agricultural/industrial or other establishment) or that connects a link between the already identified core network with higher order roads were included in the validated core network(s). Some village roads having many facilities along them were also considered for inclusion in the core network.

The workshop participants also identified the roads according to their level of priority for development. This is termed as 'local priority' in the RPPM and is one of the assessment criteria for MCA for road prioritisation. In addition, the local stakeholders also identified some roads from among the upazila and union roads that may need further improvement/upgradation in terms of geometric standards such as road width and/or pavement strengthening on a priority basis.

The following were the main outcomes of the workshops: (i) verified upazila and union core road networks, (ii) identified upazila, union and village roads that have local priorities for development, (iii) identified roads that may need further improvement/upgrading, and (iv) local inputs and data necessary for CBA and MCA analyses. The outcomes were used to update the road database. 


\section{Developing a Web-Based Application for the RPPM: Results and Discussion}

Customisation of any existing software/application was not possible to implement the methodology. Hence, our research team developed a new road network planning and prioritisation software, namely the Rural Road Planning and Prioritisation Model (RPPM), to meet the road development requirements of LGED.

The RPPM is a web-based tool designed to enhance planning and decision-making capacity in LGED. RPPM has been implemented on the GIS portal of LGED and can be used by LGED officials working at its headquarters or field offices. Its integration with the GIS portal facilitates mapping and generating road priority outputs on the web. The software can generate core road networks at upazila and union levels, and evaluate the priority of rural roads for their development, including their ranking based on the outcome of MCA and CBA analyses.

The RPPM can produce two types of outputs: lists/tables and maps. A list of roads in the core road network and eight separate priority lists for different surface types of roads and different types of development (Table 2 and Appendix B) can be produced. RPPM can produce map outputs that include Core network maps at upazila and union levels and maps showing prioritised roads on an upazila map (Appendix C).

The priority score table for a road has the following information: (i) road code and road name, (ii) roughness condition, (iii) Average Annual Daily Traffic (AADT) and Commercial Vehicle per Day (CVD) values, (iv) total road length, (v) road type, (vi) surface type, connectivity, (vii) MCA scores for facilities, (viii) evaluation score including EIRR (if and where applicable) and MCA scores and (ix) priority ranking considering EIRR or MCA.

The successful application of the methodology for the pilot district validated its applicability and the working of the RPPM. The methodology can be applied to other districts of Bangladesh and RPPM can be used to generate core networks and priority lists for road improvement and maintenance.

The RPPM generated the core road network for each upazila. The maps reveal that the core road network of the district is almost unbroken if one considers the RHD roads in the network. In some upazilas (for example, Gopalpur, Bhuapur and Mirzapur), there is scope for expanding the core network to improve rural accessibility. The number of roads in the core network varies from 10 to 39. However, the number of roads depends neither on the size nor on the road density of the upazila. The core network of Tangail district has 77 upazila roads and 154 union roads. There is no other type of road in the core network. RPPM selects only those roads in the core road network for which data are available in the road database. As data on roads maintained by RHD are not available in the database, they are not shown in the core network generated by RPPM. However, the complete core networks with the RHD roads, if any, can be seen on a computer screen by activating the RHD road layer from the GIS database of LGED.

LGED road database does not have traffic count data for all earth roads. The priority ranking for some roads may change if AADT data were available for all roads. It is found that most of the low volume earth roads have an MCA score of less than 20. There are only 90 roads with MCA scores over 20. It may be mentioned here that of these 90 roads, AADT values for 10 roads were not available.

There are 79 earth roads in the district with an AADT value of over 200. For these roads, both EIRR values and MCA scores were calculated. The highest EIRR value for a road was $33.94 \%$. It may be mentioned here that all upazilas did not have earth roads with high traffic volume. Seven upazilas in the district have high traffic volume earth roads. If the generally accepted $12 \%$ is considered as the cut-off value for EIRR, only eight roads could be selected. Most of the roads have an EIRR value below $8 \%$. Although some roads have high MCA scores (there are six roads that have an MCA score over 50), most of the roads have an MCA score below 20. It is observed that many roads with less than $12 \%$ EIRR value can have high MCA scores. This implies that such roads have significant access benefits and that the selection of roads for improvement should not always be based on their EIRR values, their MCA scores may also be considered. 
Compared to earth roads, the partially paved roads draw a much higher traffic volume. The AADT value for most of such roads is above 300; many of them also have a considerable number of commercial vehicular traffic. As the AADT values for all partially paved roads were not available, the ranking order of some of the roads may get changed if AADT values for all roads were available. If a $12 \%$ EIRR value is considered for investment, 56 partially paved roads can be considered for improvement. The MCA scores for most of the top ranked roads are high. There are more than 50 partially paved roads in Tangail with an MCA score of over 50.

RPPM assessment found 70 partially paved roads needed maintenance. Compared to partially paved roads considered for improvement, these roads have higher MCA scores.

There were 94 fully paved roads in the district that met the criteria for maintenance. As expected, these roads have a heavy volume of traffic (in terms of both AADT and CVD). These roads also have high MCA scores.

Considerable changes in traffic and other conditions such as high volume of traffic, especially heavier commercial vehicles, extreme weather conditions, etc., may require the improvement of road geometric standards, including widening of pavement and/or road crest, raising of road embankment and similar other measures for an existing road. The road surface may be fully paved, partially paved or HBB. RPPM generates a single list for all kinds of road surfaces that may require further improvement/upgrading. It is found that 19 roads in the district may need further improvement/upgrading. Except one, all roads were upazila roads. Several upazilas did not have any road for further improvement/upgrading. Although only seven roads had an EIRR value of $12 \%$ or more, most of the roads had an MCA score over 60. It may be necessary to further study the identified 19 roads before any final decision on them is considered.

\section{Conclusions}

This paper has discussed a field-tested methodology for planning and prioritisation of rural roads. The proposed model, the RPPM, has several merits over other established methods of road network planning. As opposed to the conventional approach to network planning that focuses on traffic flow with the purpose to minimize travel time and/or travel distance or maximise traffic flow capacity, the RPPM ensures local accessibility and connectivity with the greater region. The methodology is equally applicable for both low and high-volume rural roads. For example, the RPPM can prioritise rural roads with AADT as low as 50. Next, the RPPM takes into account the specific nature of road development works by considering three distinct types of prioritisation schemes. Such distinction has merits on the ground of practical application. Finally, a major barrier is the lack of sophisticated data at the rural level. In such cases, local knowledge becomes extremely important for rural road prioritisation. The strength of RPPM is that it ensures public participation through local workshops. The local workshops complement the technical process and can ensure transparency in the planning process of future road development works by LGED.

The methodology has been generalised, as far as practical, for its application in other districts of Bangladesh. A major consideration in developing the methodology was that it should not require any vast amount of new data collection; yet should be practical and be easily usable by LGED professionals. It is also worth mentioning that as the RPPM (i) does not require the collection of huge amount of data, like the existing rural road prioritisation models; (ii) optimise use of existing database; (iii) considers 'local priority' and thus ensures public participation and offset information loss due to use of much smaller amount of data; (iv) yet ensures objective decision making and (v) can calculate both MCA and EIRR, the methodology of the model can be used to replicate any other country specific model after necessary customisation. It has already been stated that India, China, Sri Lanka, Philippines all have strong rural road development programmes [6-10]. In fact, in the Philippines, the actual project selection and implementation are done by the LGUs by ranking the candidate roads through both general and specific criteria [9]. Similarly, China 
has established an institutional setup involving financial and implementation arrangements and responsibilities at different tiers of the government for the proper maintenance of rural roads [10]. The methodology of RPPM is expected to be useful in all these contexts.

An important consideration of road prioritisation is spatial unit of analysis. For example, a rural road may get a low prioritisation score for a smaller geographic unit (upazila level), presumably due to low traffic volume and low EIRR. However, considering a wider geographic scale (district level), the road may be crucially important for advancing regional accessibility. The proposed RPPM takes into account this geographic aspect by developing a core road network - a network that considers accessibility and connectivity not only within a single upazila but also with neighboring upazilas, at a wider regional scale.

Also, there may be cases where deserving roads may be prioritised low in one upazila with higher EIRR and MCA values than roads of another upazila which may be prioritised high with lower EIRR and MCA value. The decision may be based on other considerations. Except for low volume earth roads, the ranking is based on EIRR values. As the primary objective of rural road development is the improvement of accessibility, which is better reflected in MCA scores, roads that have somewhat lower EIRR values than the cut-off rate but have high MCA scores (50 or above) may be given priority for development. Thus, the generated outputs are found useful to assist in decision-making, and LGED is considering to replicate the methodology for the entire country [37].

Although vehicular emission and climate change issues have not been considered in RPPM, Core Network planning will reduce subjective and less useful development of rural road alignments and consequent land use changes. Besides, prioritised interventions will reduce vehicle operating costs and vehicular emission. Further to add, living with flood or storm drainage, a common climate change adaptation tool, can be indirectly considered by the RPPM. 'Local priority' is an important criterion of the RPPM. It has been found during local workshops that local people and leaders consider all weather connectivity, maximum flood level, storm drainage, road safety, congestion or bottleneck etc., that could not be explicitly considered in the model due primarily to lack of data. However, further research is required to estimate emission scenarios before and after the application of RPPM and other socio-economic and climate change adaptation related impacts.

Author Contributions: Conceptualisation, M.M.U.H., A.S.M.A.Q. and M.R.; Data curation, A.S.M.A.Q., M.R., T.A. and T.H.S.; Formal analysis, A.S.M.A.Q., M.R., A.H. and T.H.S.; Funding acquisition, M.M.U.H. and A.S.M.A.Q.; Investigation, M.M.U.H., A.S.M.A.Q., M.R., F.K., M.S.A., A.H., S.J., I.I. and T.H.S.; Methodology, A.S.M.A.Q., M.R., F.K., A.H. and S.J.; Project administration, M.M.U.H.; Resources, M.M.U.H., A.S.M.A.Q., M.R. and F.K.; Software, A.S.M.A.Q., M.R. and M.S.A.; Supervision, A.S.M.A.Q.; Validation, M.M.U.H., A.S.M.A.Q., M.R. and M.S.A.; Visualisation, M.R. and M.S.A.; Writing-original draft, M.M.U.H., A.S.M.A.Q., M.R., F.K., M.S.A. and A.H.; Writing-review \& editing, M.M.U.H., A.S.M.A.Q., M.R., T.A. and A.H. All authors have read and agreed to the published version of the manuscript.

Funding: This research was funded by UK aid-funded Research for Community Access Partnership (ReCAP) [grant number: BAN2072A] and the APC was funded by the same.

Institutional Review Board Statement: Not applicable.

Informed Consent Statement: Not applicable.

Data Availability Statement: Not applicable.

Acknowledgments: The methodology discussed in this article was developed for the Local Government Engineering Department (LGED) in Bangladesh. A multi-disciplinary team of Bangladesh University of Engineering and Technology (BUET), led by the experts from the Department of Urban and Regional Planning, developed the methodology and piloted it in a district. The authors gratefully acknowledge the contributions of all team members, including Sohel Rahman, Md Hadiuzzaman, Fahim Tahmid Chaudhury, Kazi Ehsanul Bari, Mujahidul Islam and Anindya Kishore Debnath; the concerned officials of LGED, including Abul Monzur Md. Sadeque; and other stakeholders in developing the methodology and its implementation and for sharing departmental information 
and database. We are also grateful to the anonymous reviewers for their valuable comments and suggestions to improve the article.

Conflicts of Interest: The authors declare no conflict of interest.

\section{Appendix A. Decision Tree Showing RPPM Methodology}

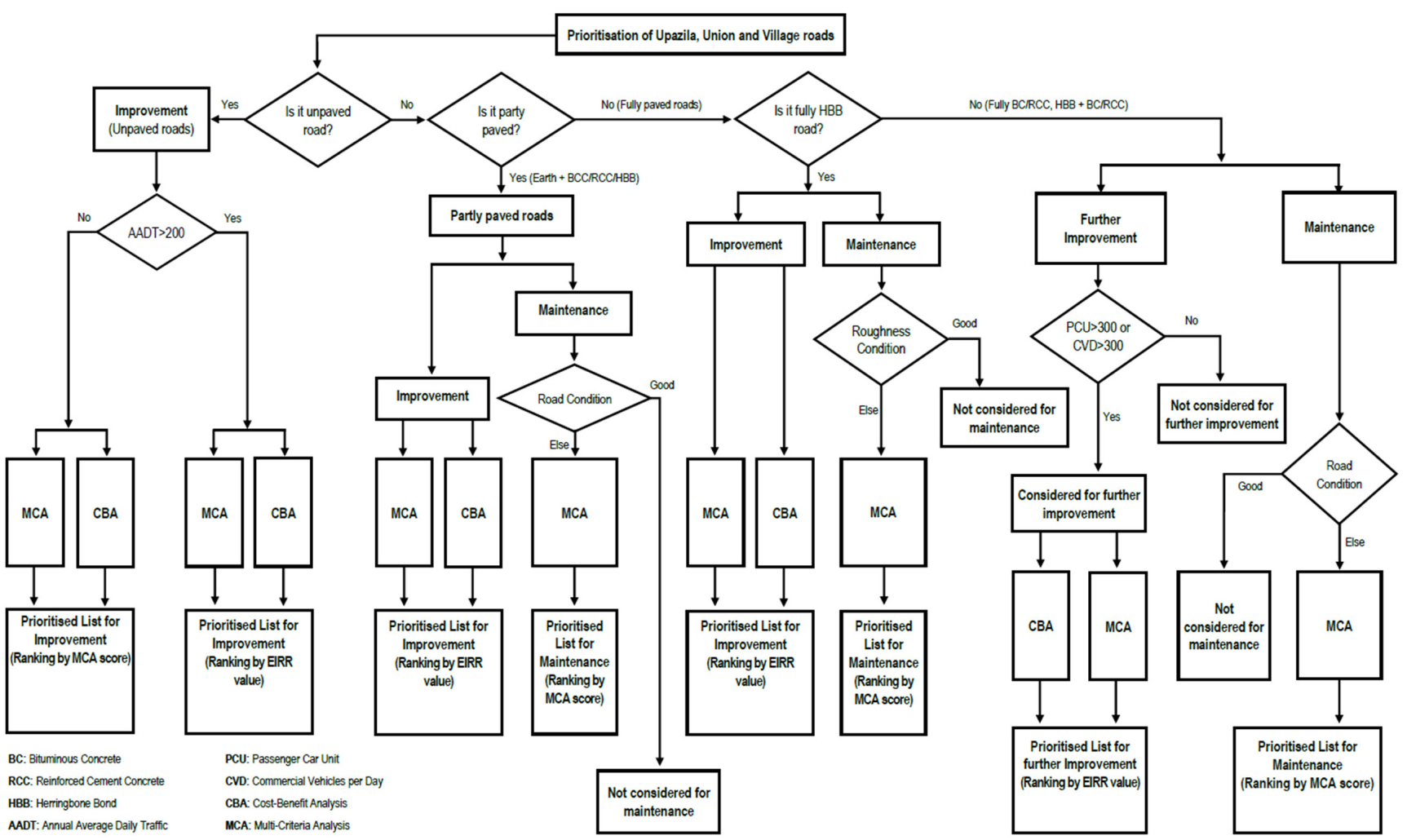

Figure A1. Decision tree showing selection of roads for development intervention and priority ranking.

Note: List of criteria is given in Table 3, in the main text.

\section{Appendix B. Samples of Lists of Tables Produced by RPPM}

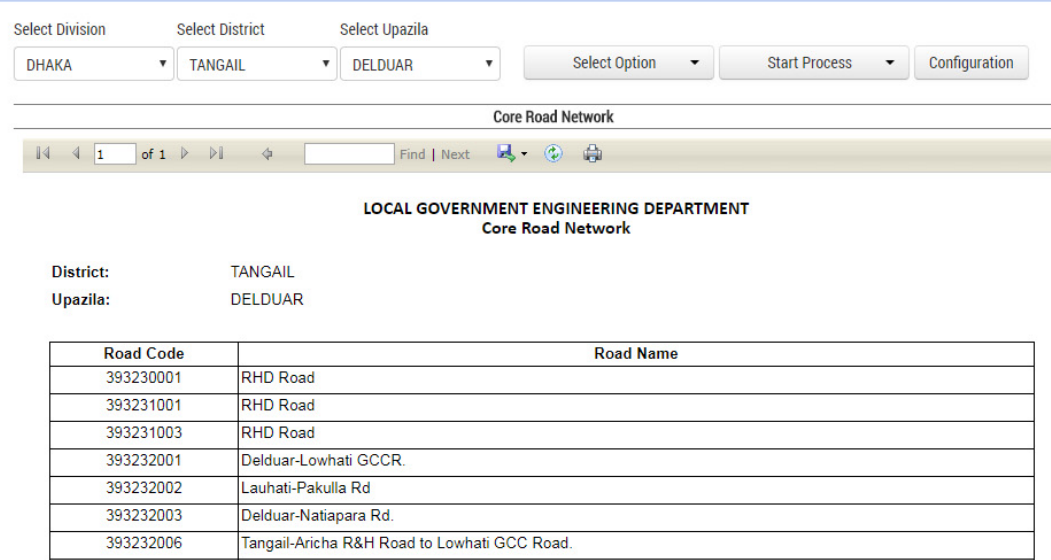

Figure A2. Output window showing list of roads forming Core Road Network in an upazila. 


\section{GIS Portal}

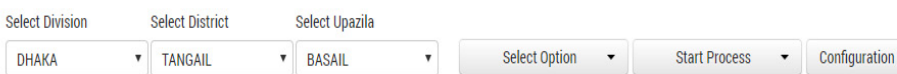

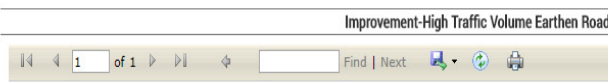

LOCAL GOVERNMENT AND ENGINEERING DEPARTMENT PRIORITY SCORE AND RANKING

District: TANGAIL $\quad$ Type of Development: Improvement

Surface Type: High Traffic Volume Unpaved Roa

\begin{tabular}{|c|c|c|c|c|c|c|c|}
\hline \multirow[t]{2}{*}{ Ranking } & \multirow[t]{2}{*}{ Road Code } & \multirow[t]{2}{*}{ Road Name } & \multirow[t]{2}{*}{ AADT } & \multirow[t]{2}{*}{ CVD } & \multirow{2}{*}{$\begin{array}{c}\text { Total } \\
\text { Length }\end{array}$} & \multicolumn{2}{|c|}{ Score } \\
\hline & & & & & & EIRR & MCA \\
\hline 1 & 393093011 & $\begin{array}{l}\text { Kanchanpur UP Office-Patherghata hat via } \\
\text { Tarabari Road. }\end{array}$ & 434 & 48 & 8.700 & 14.631 & 28.612 \\
\hline 2 & 393092009 & Ishorgonj GC-Sunna GC Road. & 388 & 30 & 3.000 & 14.386 & 75.874 \\
\hline 3 & 393093008 & Basail-Kanchanpur UP office Road. & 344 & 48 & 3.920 & 8.071 & 41.303 \\
\hline 4 & \begin{tabular}{|l}
393093014 \\
\end{tabular} & Fulkihat(Janjania)-Kawajani UP via Badiajan. & 238 & 10 & 4.000 & 5.757 & 28.74 \\
\hline 5 & 393094024 & Karatia-Saysata via Sonalia Road. & 202 & 19 & 2.700 & 2.760 & 5.538 \\
\hline 6 & 393094001 & \begin{tabular}{|l|} 
Singerdak-Saydampur-Haluapara. \\
\end{tabular} & 350 & 7 & 8.410 & 0.000 & 2.319 \\
\hline
\end{tabular}

Figure A3. Output window showing priority List for Improvement of High Traffic Volume Earth Road.

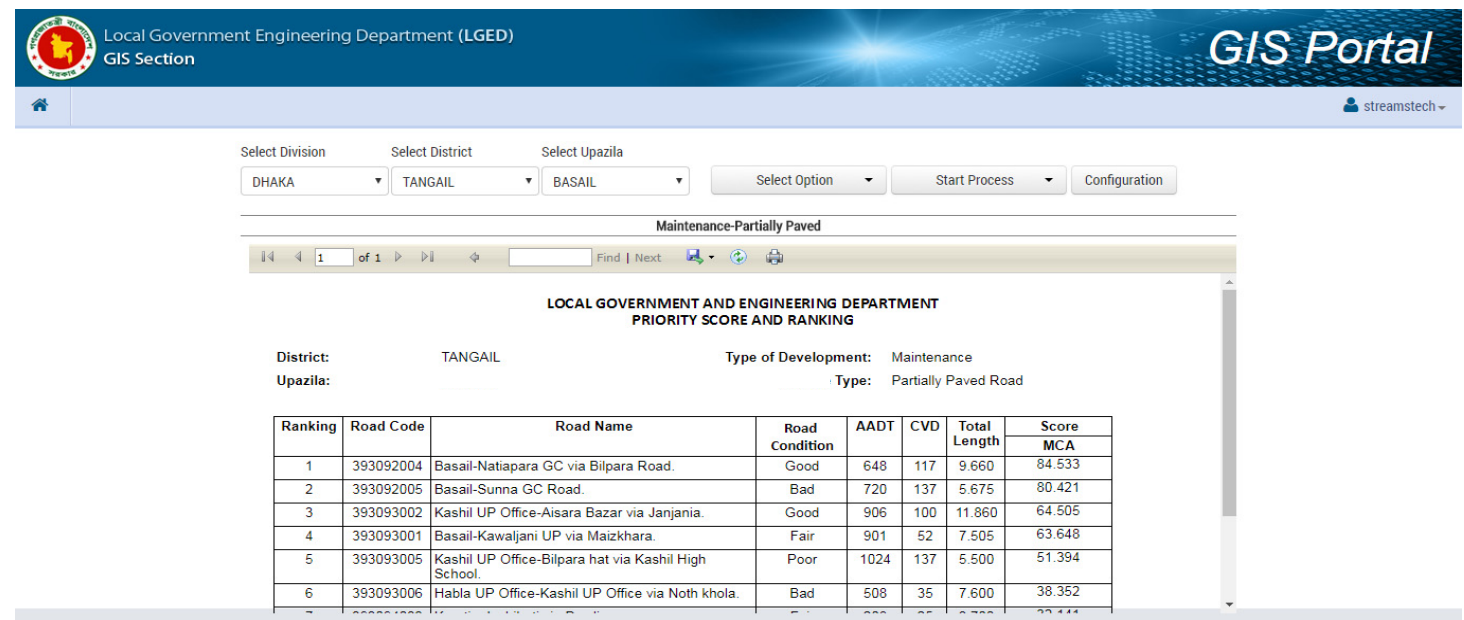

Figure A4. Output Window Showing Priority List for Maintenance of Partially Paved Roads.

Appendix C. Samples of Maps Produced by RPPM

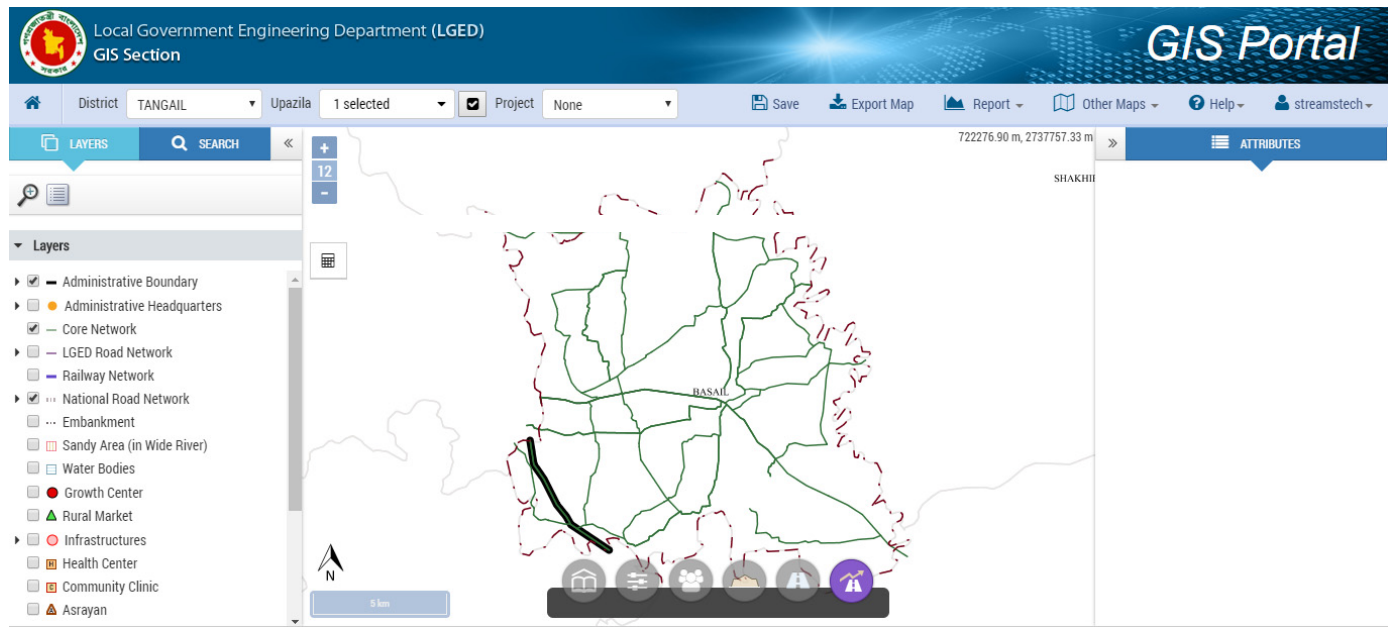

Figure A5. Map Window Showing the Core Roads Network. 


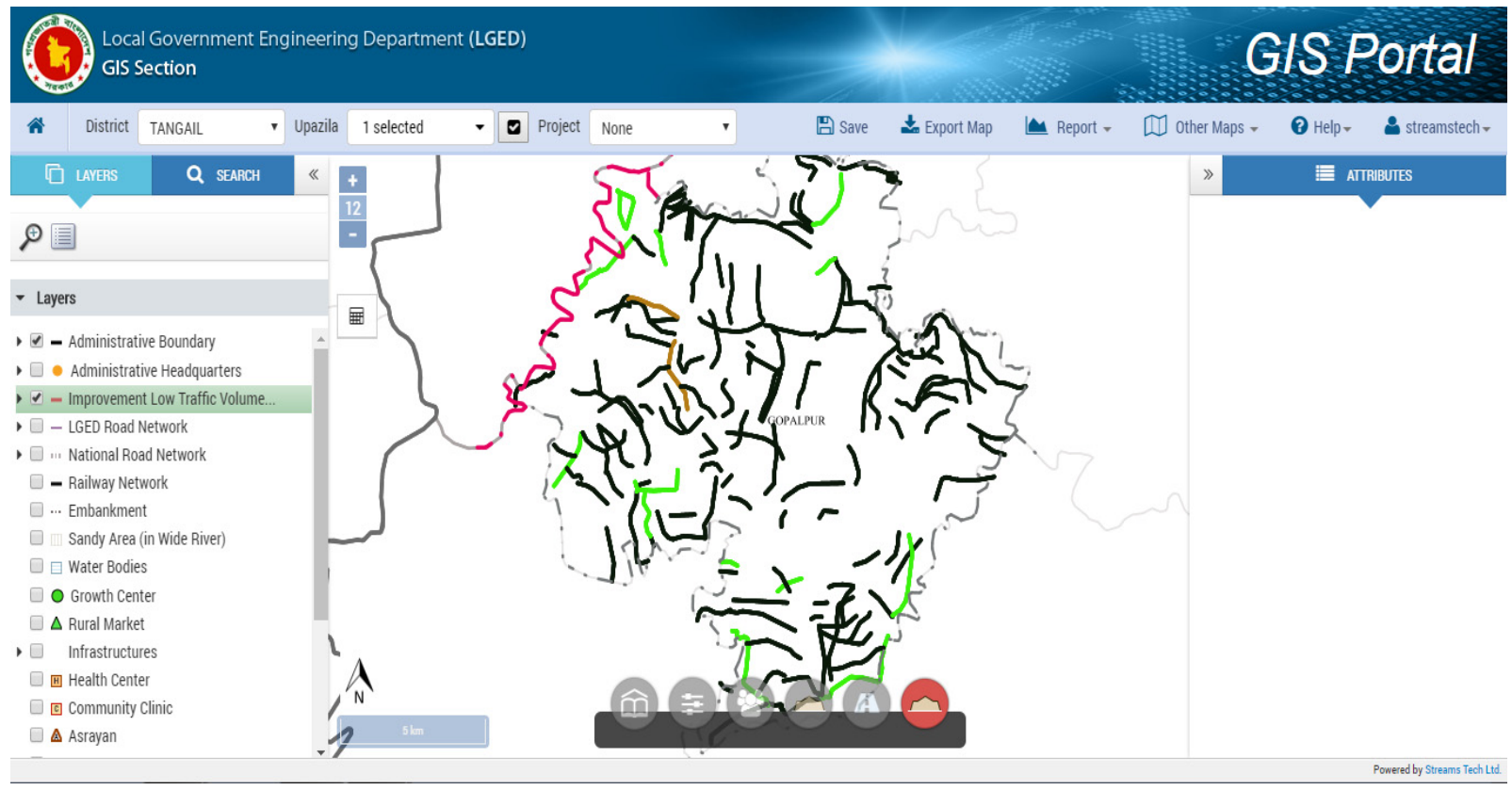

Figure A6. Map Window Showing the Low Volume Roads for Improvement.

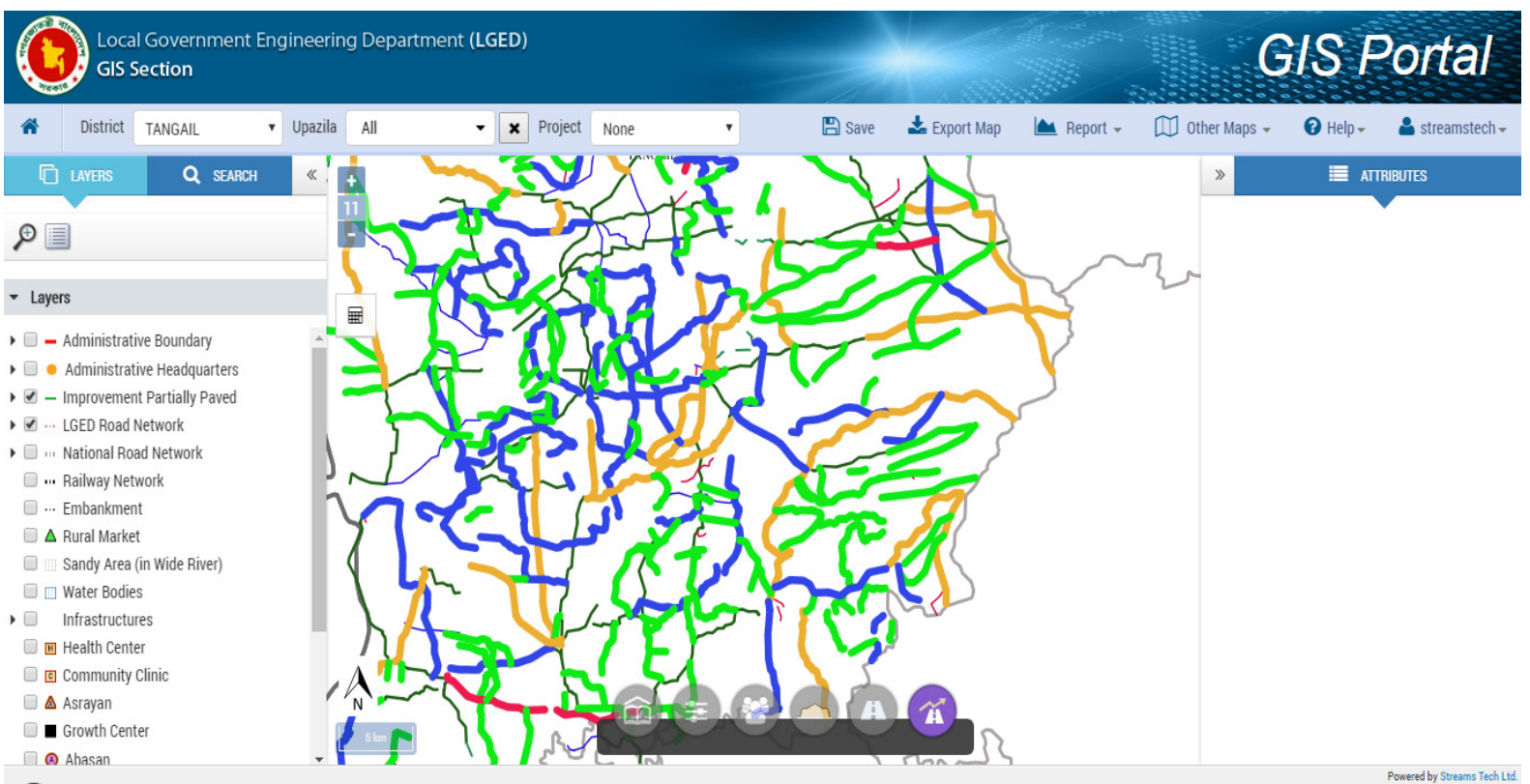

Figure A7. Map Window Showing the Partially Paved Roads for Improvement.

\section{References}

1. Lu, X.; Jones, S.; Li, L. Promoting economically equitable rural road development: Case study among Chinese provinces. Transp. Dev. Econ. 2018, 4, 3. [CrossRef]

2. Olsson, J. Improved road accessibility and indirect development effects: Evidence from rural Philippines. J. Transp. Geogr. 2009, 17, 476-483. [CrossRef]

3. Sewell, S.J.; Desai, S.A.; Mutsaa, E.; Lottering, R.T. A comparative study of community perceptions regarding the role of roads as a poverty alleviation strategy in rural areas. J. Rural Stud. 2019, 71, 73-84. [CrossRef]

4. Zhou, Z.; Duan, J.; Li, W.; Geng, S. Can Rural Road Construction Promote the Sustainable Development of Regional Agriculture in China? Sustainability 2021, 13, 10882. [CrossRef]

5. Shrestha, J.K.; Benta, A.; Lopes, R.B.; Ferreira, C.; Lopes, N. Covering-based rural road network methodology for hilly regions of developing countries: Application in Nepal. J. Transp. Eng. Part A Syst. 2017, 143, 04016010. [CrossRef] 
6. NRRDA. Operation Manual; National Rural Road Development Agency, Ministry of Rural Development, Government of India: Delhi, India, 2005.

7. GoI. Eleventh Five Year Plan (2007-2012), Volume III; Chapter 9; Planning Commission, Government of India: Delhi, India, 2008. Available online: http:/ / planningcommission.nic.in/plans/planrel/fiveyr/welcome.html (accessed on 29 January 2017).

8. GoSL. Annual Report 2008; Ministry of Finance and Planning Government of Sri Lanka: Colombo, Sri Lanka, 2008.

9. PRDP. The I-BUILD Operations Manual; Philippine Rural Development Project; Government of Philippines: Manila, Philippines, 2015.

10. Hongye, F. Rural road maintenance in China. In Transport and Communications Bulletin for Asia and the Pacific; No. 81, Planning for Accessibility and Rural Roads; 2012; Available online: http://www.unescap.org/sites/default/files/bulletin81_Article-4.pdf (accessed on 29 January 2017).

11. Li, Y.; DaCosta, M.N. Transportation and income inequality in China: 1978-2007. Transp. Res. Part A Policy Pract. 2013, 55, 56-71. [CrossRef]

12. Farahani, R.Z.; Miandoabchi, E.; Szeto, W.Y.; Rashidi, H. A review of urban transportation network design problems. Eur. J. Oper. Res. 2013, 229, 281-302. [CrossRef]

13. Hine, J.; Simon, E.; Done, S.; David, K. Ghana Feeder Road Prioritisation. 2002. Available online: https://www.piarc.org/ ressources/documents/actes-seminaires0102/c3c20-cambodge02/9127,2.2_TC3-20_2002_Hine.pdf (accessed on 29 April 2017).

14. Yedla, S.; Shrestha, R.M. Multi-criteria approach for the selection of alternative options for environmentally sustainable transport system in Delhi. Transp. Res. Part A Policy Pract. 2003, 37, 717-729. [CrossRef]

15. Singh, A.K. GIS Based Rural Road Network Planning for Developing Countries. J. Transp. Eng. 2010, 142. [CrossRef]

16. Archondo-Callao, R. The Roads Economic Decision Model (RED) for the Economic Evaluation of Low Volume Roads-Software User Guide E Case Studies; SSATP Working Paper No. 78; World Bank: Washington, DC, USA, 2004.

17. LGED. LGED Road Database. 2020. Available online: http:/ / oldweb.lged.gov.bd/ViewRoad2.aspx (accessed on 30 June 2020).

18. Planning Commission. The Seventh Five Year Plan: FY2016-FY2020; Government of Bangladesh: Dhaka, Bangladesh, 2015.

19. LGRDC. Guidelines for Rural Roads and Culverts Maintenance; Local Government Division, Ministry of Local Government, Rural Development and Cooperatives, Government of Bangladesh: Dhaka, Bangladesh, 2013.

20. LGED; JICA. Road Design Standards—Rural Road; LGED and JICA: Dhaka, Bangladesh, 2005.

21. LGED. Roads and Structure Database Management System (RSDMS); LGED: Dhaka, Bangladesh, 2016.

22. Haggett, P.; Gunawardena, K.A. Determination of Population Thresholds for Settlement Functions by the Reed-Muench Method. Prof. Geogr. 1964, 16, 6-9. [CrossRef]

23. World Bank. Toolkit for the Economic Evaluation of World Bank Transport Projects; World Bank: Washington, DC, USA, 2003.

24. World Bank. HDM 4-Introduction (Powerpoint Slides). 2008. Available online: http://web.worldbank.org/WBSITE/ EXTERNAL/TOPICS/EXTTRANSPORT/EXTROADSHIGHWAYS/0,,contentMDK:22011461 \{\}pagePK:148956 \{\}piPK: 216618 \{\}theSitePK:338661,00.html\#downloads (accessed on 29 April 2016).

25. Hiep, V.D. HDM-4, dTIMS-CT, EHERST Tools for Asset Management; Saitama University: Saitama, Japan, 2006; Available online: http://www.academia.edu/1734546/Comparison_between_HDM-4_dTIMS-CT_and_HERS-ST_Tools_for_Asset_ Management (accessed on 29 April 2016).

26. Archondo-Callao, R. Roads Economic Decision Model (RED) for Economic Evaluation of Low Volume Roads; Sub-Saharan Africa Transport Policy Program (SSATP) Technical Note; No. 18; World Bank: Washington, DC, USA, 1999.

27. ESCAP. Feeder Road Appraisal; Report on Seminar cum Study Tour on Economic and Technical Aspects of the Construction of Local Roads and Rural Transport; United Nations: Bangkok, Thailand, 1979; pp. 285-294.

28. Greenstein, J.; Bonjack, H. Socio-economic evaluation and upgrading of rural roads in agricultural areas of Ecuador. Proceedings of the 3rd Low Volume Roads Conference. Transp. Res. Rec. 1983, 898, 88-94.

29. UNCHS. Guidelines for the Planning of Rural Settlements and Infrastructure: Road Networks; UNCHS: Nairobi, Kenya, 1985.

30. Lebo, J.; Schelling, D. Design and Appraisal of Rural Transport Infrastructure, Ensuring Basic Access for the Rural Communities; Technical Paper No. 496; World Bank: Washington, DC, USA, 2001.

31. Oudheusden, D.L.; Khan, L.R. Planning and development of rural road networks in developing countries. Eur. J. Oper. Res. 1987, 32-33, 353-362. [CrossRef]

32. Shrestha, J.K.; Benta, A.; Lopes, R.B.; Lopes, N. A Methodology for Definition of Road Networks in Rural Areas of Nepal. Int. J. Civil Environ. Struct. Constr. Archit. Eng. 2013, 7, 422-426.

33. Gühnemann, A.; Laird, J..; Pearman, A.D. Combining cost-benefit and multi-criteria analysis to prioritise a national road infrastructure programme. Transp. Policy 2012, 23, 15-24. [CrossRef]

34. Shrestha, C.B. Developing a computer-aided methodology for district road network planning and prioritisation in Nepal. Transp. Res. Board 2003, 3, 157-174.

35. Donnges, C. Rural transport and local government units: How to improve rural transport for the rural poor? Transp. Commun. Bull. Asia Pac. 2001, 71, 19-27. Available online: www.unescap.org/ttdw/Publications/TPTS_pubs/TxBulletin_71/bulletin71_c.pdf (accessed on 29 April 2017).

36. Sarkar, A.K.; Dash, M. Quantification of Accessibility and Prioritization of Villages for Local Level Planning. Transp. Commun. Bull. Asia Pac. 2011, 81, 1-22.

37. LGRDC. 'Amar Gram Amar Shohor': Protiti Grame Adhunik Nogor Subidha Somprosharoner Kormoporikolpona; Ministry of Local Government, Rural Development and Cooperatives (LGRDC), Government of Bangladesh: Dhaka, Bangladesh, 2020. (In Bangla) 